Supporting Information

\title{
Azobenzene Molecular Trigger Controlling Phase Transitions of PNIPAm in Ionic Liquids and Light Controlled Adhesiveness
}

Caihong Wang ${ }^{a}$, Peiqi Li $^{a}$, Shiguo Zhang, Guoqiang Zhang ${ }^{c}$, Shuai Tan ${ }^{a}$, Yong Wu*, Masayoshi Watanabe

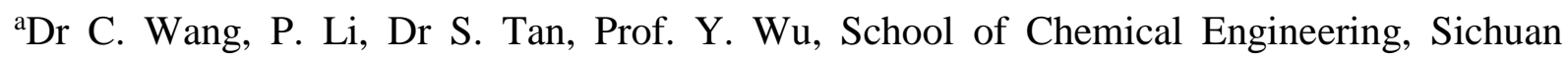
University, No.24 South Section 1, Yihuan Road, Chengdu 610065, China

${ }^{b}$ Prof. S. Zhang, College of Materials Science and Engineering, Hunan University, No. 2 Lushan Road (S), Yuelu District, Changsha 410082, China

${ }^{\mathrm{c}}$ Dr G. Zhang, Department of Macromolecular Science and Engineering, Case Western Reserve University, Cleveland, OH 44106-7202, United States

${ }^{\text {d} P r o f . ~ M . ~ W a t a n a b e, ~ D e p a r t m e n t ~ o f ~ C h e m i s t r y ~ a n d ~ B i o t e c h n o l o g y, ~ Y o k o h a m a ~ N a t i o n a l ~}$ University, 79-5 Tokiwadai, Hodogaya-ku, Yokohama 240-8501, Japan 
(a)

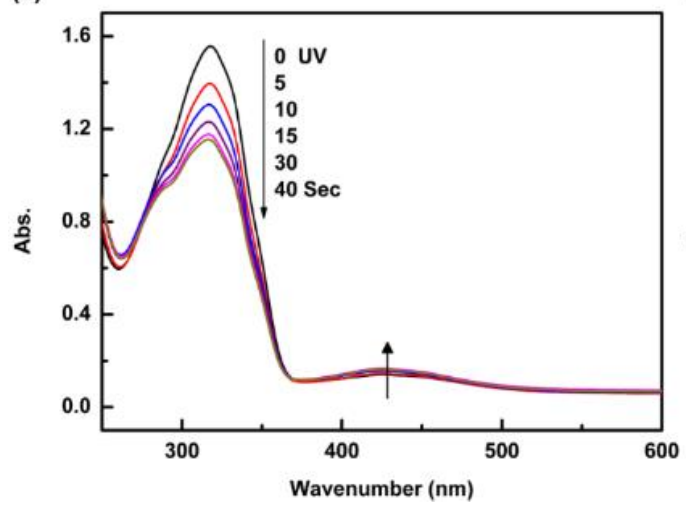

(b)

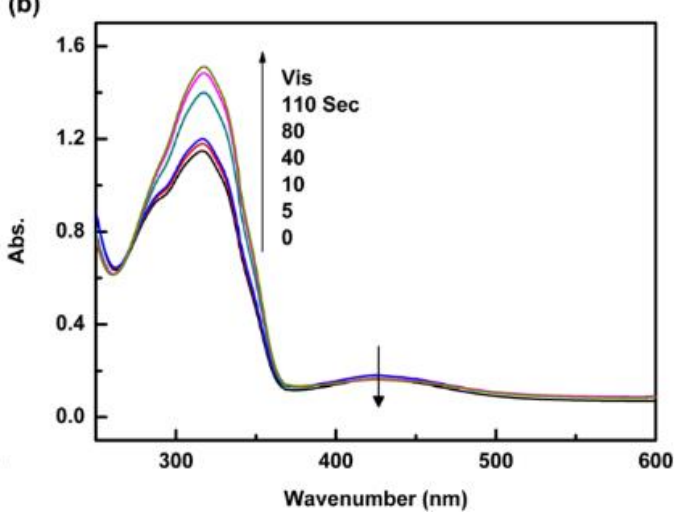

Figure S1. UV-vis spectra of photoisomerization of Azo in $\left[\mathrm{C}_{2} \mathrm{mim}\right]\left[\mathrm{NTf}_{2}\right]\left(10^{-4} \mathrm{~mol} / \mathrm{L}\right)$ under UV (a) and visible light irradiation (b).

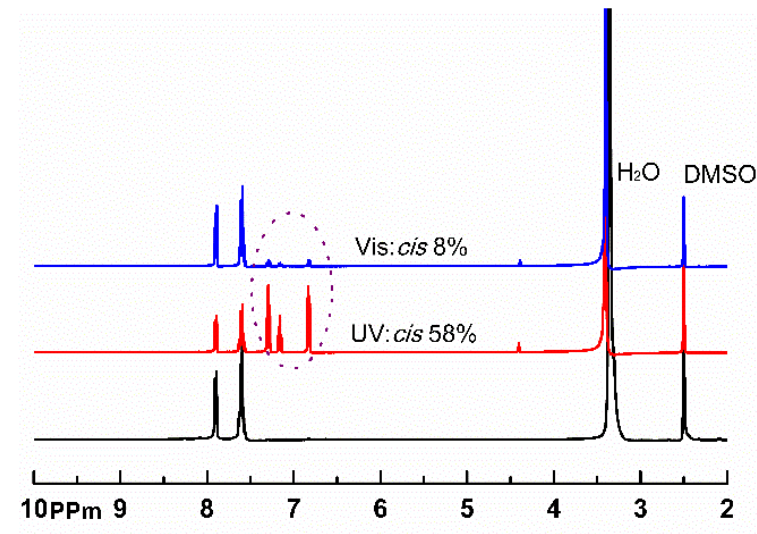

Figure S2. ${ }^{1} \mathrm{H}$ NMR spectra of Azo in DMSO (0.4 wt $\left.\%\right)$ in the dark, under UV and visible light irradiations.

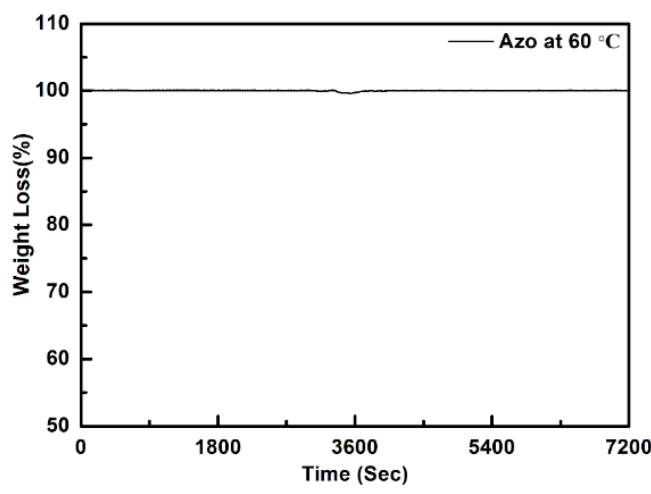

Figure S3. Weight loss of Azo in $\left[\mathrm{C}_{2} \mathrm{mim}\right]\left[\mathrm{NTf}_{2}\right]$ keeping at $60^{\circ} \mathrm{C}$ for $2 \mathrm{~h}$. 


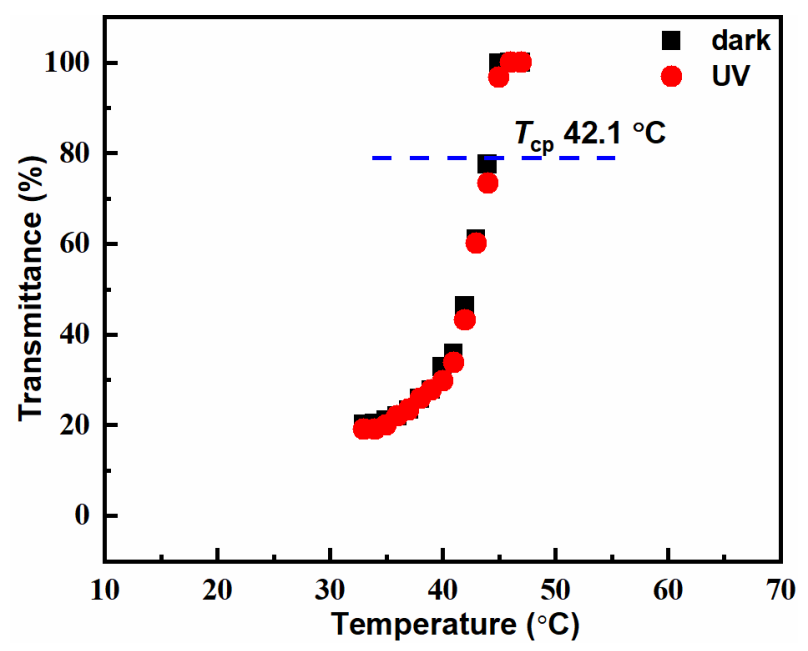

Figure S4. Temperature dependence of transmittance for $7 \mathrm{wt} \%$ PNIPAm in neat $\left[\mathrm{C}_{2} \mathrm{mim}\right]\left[\mathrm{NTf}_{2}\right]$ at a cooling rate of $1^{\circ} \mathrm{C} \mathrm{min}^{-1}$ in the dark and under UV. $\Delta T_{\mathrm{cp}}$ is zero in absence of Azo. 

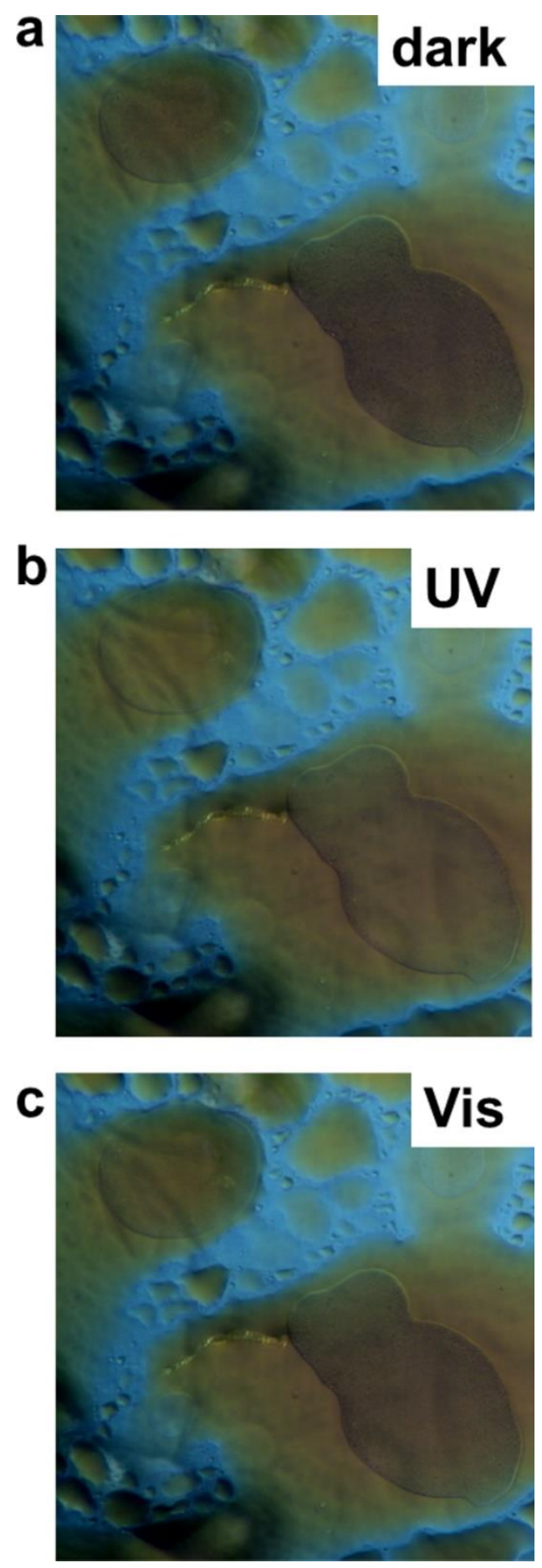

Figure S5. 3wt $\%$ PNIPAm in $97 \mathrm{wt} \%$ Azo at $90^{\circ} \mathrm{C}$ in the dark (a), under UV (b) and under visible light irradiations (c). The brown parts are ascribed to aggregated particles of PNIPAm in melting Azo solvent and they become transparent under UV irradiation for 5 mins, indicating that PNIPAm is soluble in cis-Azo dominated solvent while insoluble in trans-Azo dominated solvent. 


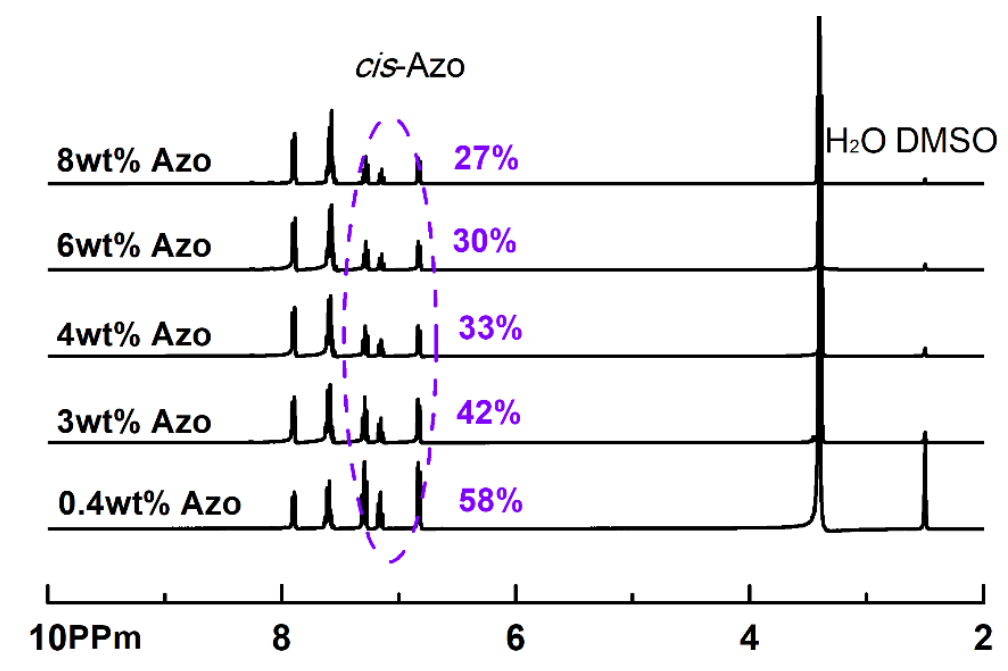

Figure S6. ${ }^{1} \mathrm{H}$ NMR spectra of $c i s-A z o$ for Azo in DMSO with different concentrations at room temperature after UV irradiation.

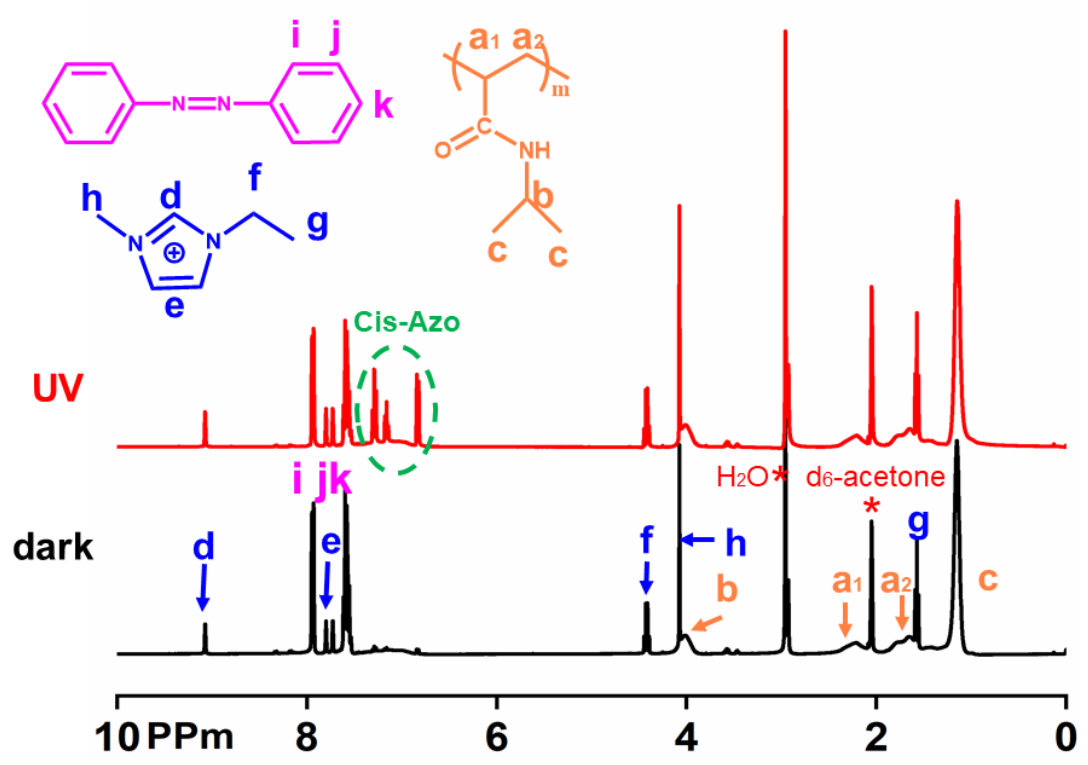

Figure S7. ${ }^{1} \mathrm{H}$ NMR spectra of the polymer solution in $\mathrm{D}_{6}$-actone in the dark and under UV irradiation.

The weight ratio of Azo/PNIPAm/IL is 3/4/3 in order to balance peak intesities in the spectra. It should be noted that signal of the proton corresponding to N-H of PNIPAm could not be detected by ${ }^{1} \mathrm{HNMR}$ due to an electron drawing effect of $\mathrm{C}=\mathrm{O}$ group. 
(a)

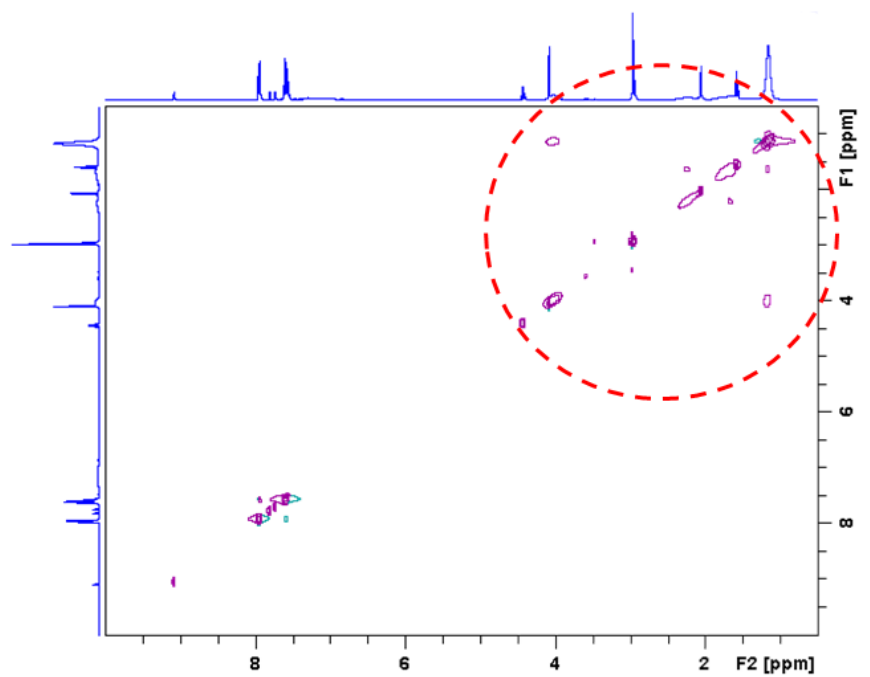

(b)

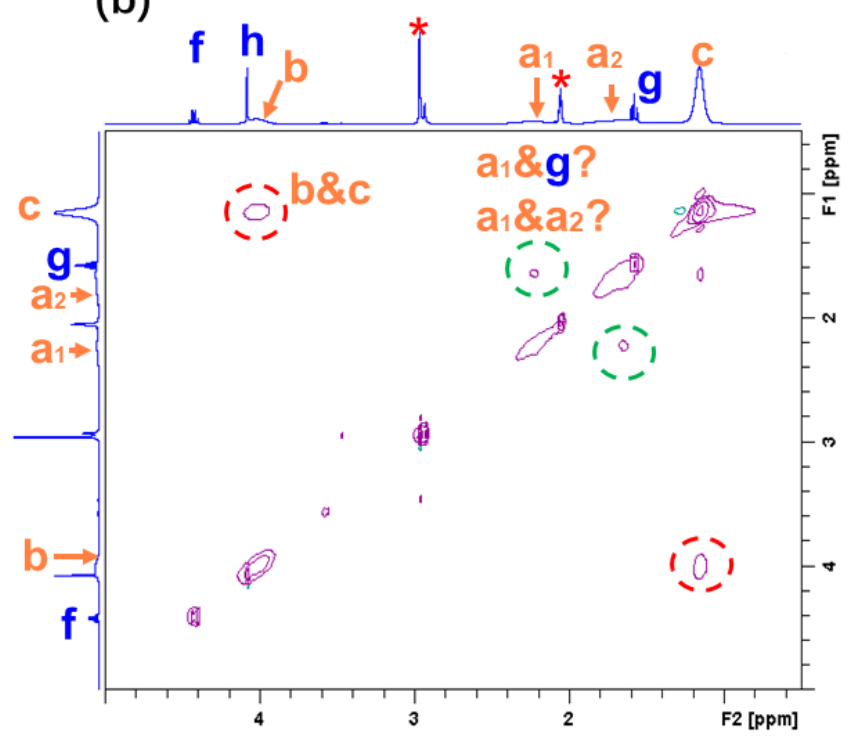

Figure S8. 2D NOSEY NMR spectra of the polymer solution in the dark from 10.0 to $0.5 \mathrm{ppm}$ (a) and from 5.0 to $0.5 \mathrm{ppm}(\mathrm{b})$.

In Figure S8a, the cross peaks appeard in the region aound aromatic were ascribed to $\pi-\pi$ stacking of Azo. In Figure S8b, red dot circle correspeonded to the intramolecular dynamic of methyl groups of PNIPAm, while other cross peaks (green dot circle) remianed ambiguous. It was difficult to define the molecular interply due to a overplaped chemical-shifts of the cation and PNIPAm. 


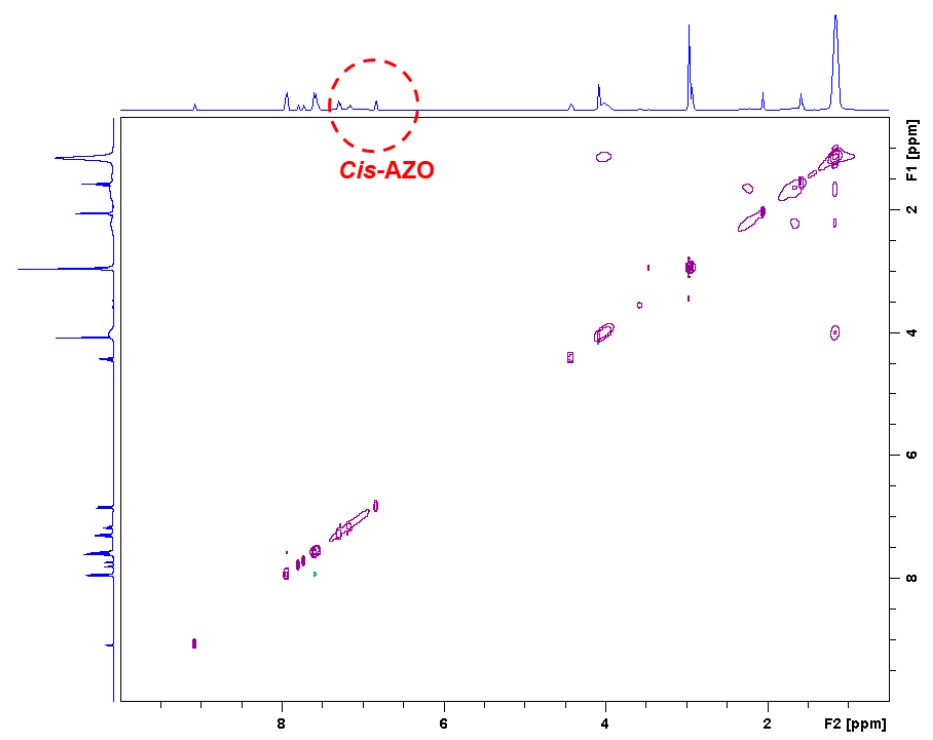

Figure S9. 2D-NMR NOSEY spectrum of the polymer solution under UV from 10.0 to 0.5 ppm.

In comparison with Figure S8, no change was observed except for appearance of the cis-Azo peak. Perhaps, due to a dilution effect, the distance between polymer, IL and Azo was too far away to interplay with each other either in the dark and under UV.

(a)

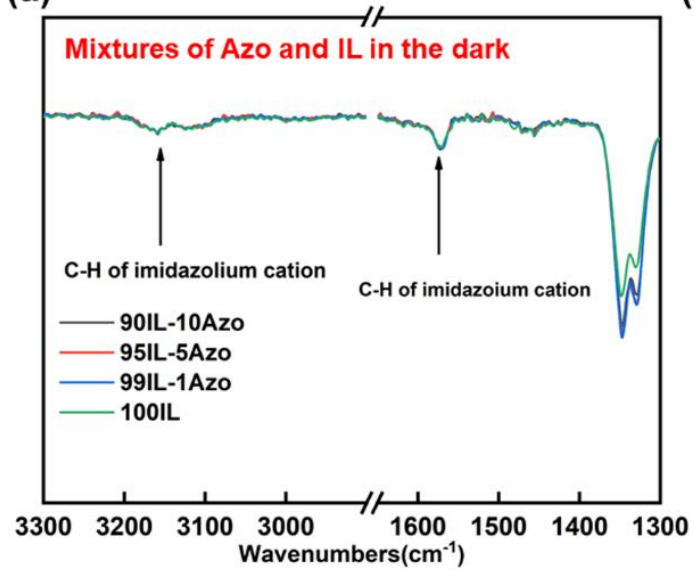

(b)

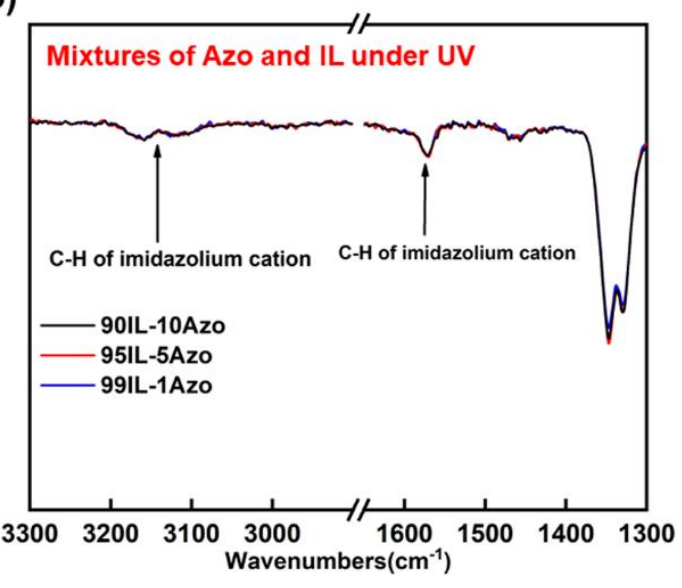

Figure S10 FT-IR spectra of mixed Azo and IL in various weight ratios at room temperature in the dark (a) and under UV irradiation(b). 90IL-10Azo means $90 \mathrm{wt} \% \mathrm{IL}$ and $10 \mathrm{wt} \%$ Azo. 


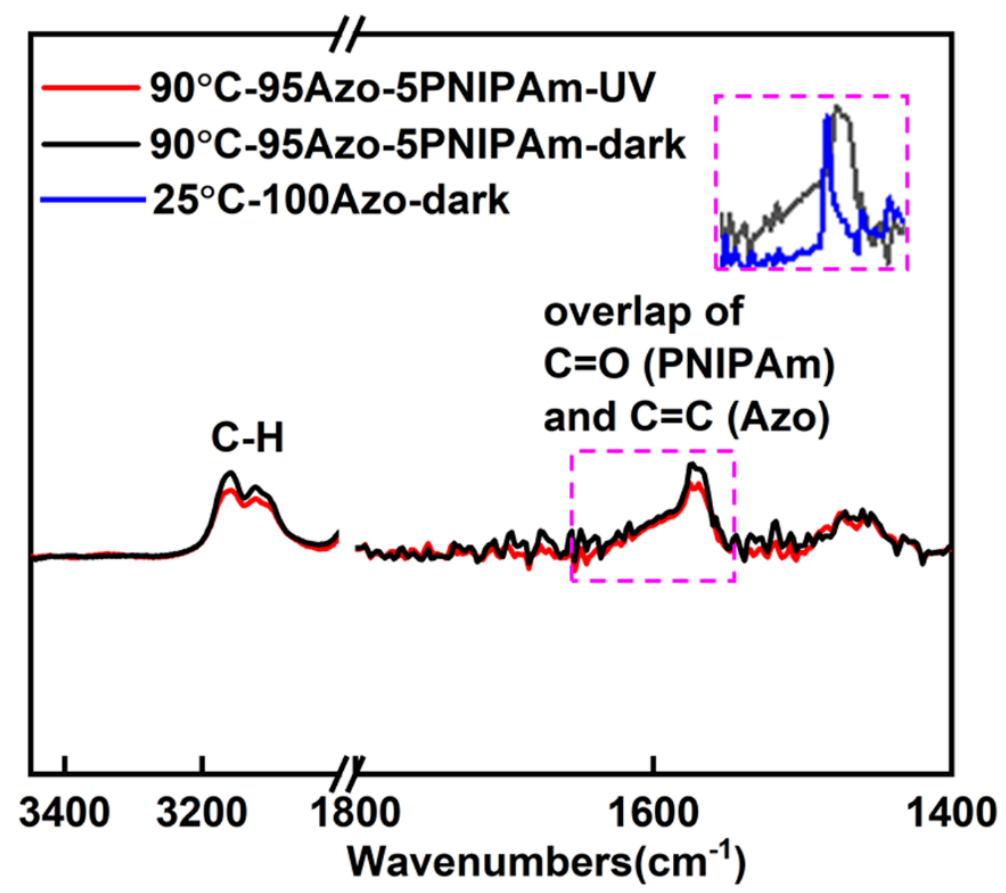

Figure S11 FT-IR spectra of Azo containing $5 \mathrm{wt} \%$ PNIPAm at $90{ }^{\circ} \mathrm{C}$ in the dark and under UV irradiation.

Table S1 $T_{\mathrm{cp}}$ for different molecular weights of PNIPAm in IL containing 1wt $\%$ Azo.

\begin{tabular}{cccc}
\hline Molecular weight & $\begin{array}{c}\text { Weight ratio of } \\
\text { PNIPAm-Azo-IL }\end{array}$ & $\begin{array}{c}\text { Trans- } T_{\mathrm{cp}} \\
\left({ }^{\circ} \mathrm{C}\right)\end{array}$ & $\begin{array}{c}\text { cis- } T_{\mathrm{cp}} \\
\left({ }^{\circ} \mathrm{C}\right)\end{array}$ \\
\hline $81 \mathrm{kDa}($ Đ: 2.5$)$ & $7-1-92$ & 45 & 34.5 \\
$25 \mathrm{kDa}$ (Đ: 2.9) & $7-1-92$ & 41.8 & 33.2 \\
\hline
\end{tabular}

Table S2 FT-IR peaks of the mxiture of PNIPAm/Azo/IL.

\begin{tabular}{ll}
\hline Wavenumber $\mathrm{cm}^{-1}$ & Peak \\
\hline 3387 & $v\left(\mathrm{~N}-\mathrm{H} \cdots\left[\mathrm{NTf}_{2}\right]\right)$ \\
3297 & $v(\mathrm{~N}-\mathrm{H} \cdots \mathrm{C}=\mathrm{O})$ \\
$1700-1640$ & $v(\mathrm{C}=\mathrm{O})(\mathrm{C}=\mathrm{O} \cdots \mathrm{N}-\mathrm{H} ; \mathrm{C}=\mathrm{O} \cdots$ Cations $)$ \\
1739 & $v(\mathrm{C}=\mathrm{O})($ unconjugated $\mathrm{C}=\mathrm{O})$ \\
\hline
\end{tabular}

